\title{
Optimal Performance in Means-Ends Activities: On the Emergence of Self-Other/World Differentiation in Infancy
}

\author{
Despina Stamatopoulou \\ University of Crete, Department of Philosophy and Social Studies, Rethymno, Greece. \\ Email: stamatop@phl.uoc.gr
}

Received October $1^{\text {st }}$, 2012; revised October 31 ${ }^{\text {st }}$, 2012; accepted November $30^{\text {th }}$, 2012

\begin{abstract}
We know little about the role of background positive affectivity and flow experiences in early development concerning means-ends activities and their possible contribution regarding symbolic functioning and the consolidation of the self as agent. The theoretical argument presented here is that a deeper appreciation of the benefits and challenges of optimal experience may help built a more unified account of optimal functioning in development. That is, the paradox of control in flow, and its relational/mirroring structure, wherein the demands of the structure (means) are entities in themselves (ends), mark possibilities for the temporal organization of experience when fine motor tuning and gross motor intention overlap. When means-focused action/temporal regulation (I) and ends-focused action (Me) become synchronized in an integrated embodied system, the system shifts experience to the experiential gear. Means-ends dynamics, then, via mirroring processes organized in turn-taking flow structures between formative action (means) and production, push the child's primary reactive space to be converted into the child's interactive experiential space and in turn mapped on and gradually transformed to the "secondary", communicative/expressive space, which also controls its manifestation, initiating in line conscious control and self-referential intentionality.
\end{abstract}

Keywords: "Means-Ends” Dynamics; Optimal Experience; Background Positive Affectivity; Self-Referential Intentionality; Symbol Formation

\section{Introduction}

Csikszentmihalyi (1975) introduced the concept of flow to designate the subjective experience that accompanies performance in a situation where challenges are matched with the person's skills. Flow is an optimal psychological state described at length by Csikszentmihalyi (e.g., 1975, 1988, 1993) and substantiated in a variety of settings (see Csikszentmihalyi, 1997; Jackson, 1992; Kerr, 1997). The original account of flow has proven remarkably robust confirmed through studies of art and science (Chiskentmihalyi, 1998). Throughout 80s and 90s the concept was embraced by researchers studying optimal experience (e.g., sports and leisure) (Jackson, 1992) or peak experience (e.g., aesthetic experience) (Chiskentmihalyi \& Robinson, 1990; Stamatopoulou, 2004) and more recently by researchers working in contexts fostering positive experience. Flow research and theory had their origin in a desire to understand this phenomenon of intrinsically motivated or autotelic experience which is intrinsically rewarding (activity rewarding in and of itself quite apart from any extrinsic goals).

Chiskentmihalyi, adopting an experiential perspective, investigated the nature and conditions of flow experience forming a picture of the characteristic qualities of optimal experience. When in flow, a person becomes totally involved being absorbed in the activity and undergoes a number of positive experiences, including freedom from self-consciousness/loss of ego, great enjoyments of the process, clarity of goals and knowledge of performance, complete concentration, feelings of control, and a sense of being totally in tune with the performance. Theoretically, flow as an optimal mental state, would be expected to be associated with optimal performance as well as providing an optimal experience. More specifically, at the individual level optimal experience has to be contextualized in the theoretical frame of daily psychological selection (Csikszentmihalyi \& Massimini, 1985). Psychological selection results from the individual's differential investment of attention and resources on the information available in their environment which also controls its manifestation.

Owing to its positive psychological features, optimal experience has been sometimes misunderstood as a state which automatically brings about well-being and development. Several studies have disconfirmed this assumption, showing that the outcomes of optimal experience are not automatically positive (Delle Fave, 2007). Rather, they vary according to the features of the associated activities; to the developmental level of skills and their potential goodness of fit, and to the value system of the cultural environment (see for an extended review see: Delle Fave, 2007). A large number of studies conducted in the last twenty years shows that flow is a multifaceted experiential state, in which cognitive, motivational and emotional components coexist in a coherent and complex reciprocal integration (Della Fave, 2007; Delle Fave \& Massimini, 2005; Delle Fave, Bassi, \& Massimini, 2008). Thus, we cannot assume a direct relation between flow, positive experience and development.

However, what do we know about the relationship between optimal experience, symbol formation, meaning making, goal setting and pursuit? Within the framework of psychological selection, and taking into account the dynamic features of the meaning-making process, optimal experience can be considered both an antecedent and an outcome (Delle Fave , 2007). Due to 
psychological rewards provided by this condition, the associated activities will be preferentially replicated and cultivated in the long run, thus affecting the developmental trajectory of the individuals and their social participation and integration. How, then, could we approach the emergence of optimal experience in the very early years of the individual's developmental trajectory? The paradox here is that flow, although relational in structure, is considered a private experience. To put it simply, how objectivity can be based in intense subjectivity? Furthermore, how from the immediate mean-ends experience could we move towards the symbolic mind-do we need a differentiation mechanism that originates this passage?

The argument presented proposes that probably a deeper appreciation of the benefits and inherent challenges (e.g., the experiential perspective and its embodied/perspectival nature) of the optimal experience may help built a more unified approach to the possible linkage of flow to the emergence of the embodied/experiential self and its centrality in the definition of intentionality and agency that function as cornerstones in symbolic functioning across development. This early developmental passage is rather missing from the flow framework, with the exception of Fogel's approach on developmental change in interpersonal settings and that of Csikszentmihalyi's theoretical account on the origins of psychological complexity (1998). Meanwhile, developmental researchers are quite reluctant to use this framework. In fact, we are in need of more developmental approaches to the emergence of flow, while reconsidering the compatibility of flow literature to early development. By implication many new methods should be developed that bear more sensitivity to capturing lived experience of the very young child. This article thus is a theoretical attempt to offer an alternative reading of flow experience in relation to optimal performance in means-ends activities in infancy, illustratively using some relevant piece of work that deals with flow in early development.

\section{Previous Attempts to Link Immediate Flow Experience and Symbolic Meaning in Development}

In a more theoretical manner, besides James' early accounts on the linkage of immediate experience to symbolic mind, Csikszentmihalyi (1998) subscribes to the view that evolution proceeds in the direction of increasing complexity; that is, toward continuous differentiation and integration. The realization of complexity is the benchmark for measuring evolutionary success (but see also Werner \& Kaplan, 1963). "Differentiation" refers to the degree to which a system is composed of parts that differ in structure or function from one another. "Integration" refers to the extent to which the different parts become hierarchically integrated and qualitatively transformed as to communicate and enhance one another's goals. A system that is more differentiated and integrated than another is said to be more complex. Both these tendencies are evident in optimal experience according to Csikszentmihalyi (1998). Finding new challenges, developing new skills, opening one to novel experiences-these are all differentiating functions. The incorporation of skills and experiences into the wholeness of one's being brings order to consciousness and harmony to actions; that is, it enhances integration. The motivation to persist in or return to the activity arises out of the activity itself. In this way, the enjoyment that flow brings is the manifestation of our evo- lutionary predilection for complexity. The movement toward complexity is not inevitable, however. "The course of evolution”, Csikszentmihalyi writes (1998), “appears to be exceedingly erratic, full of false starts and temporary reversals”. The development of complex structures, whether biological, psychological or social, takes place against the backdrop of entropy - the tendency of systems to decay and dissolve into randomness.

An other important exception in this context is the work of Fogel and colleagues (Messinger, Fogel, \& Dicson, 1997; Lavelly \& Fogel, 2005). Their work addressed micro-level assessment of infant smiles and positive communication so as to reach synchrony (defined as a continuous "dance" between two partners and evolved on the basis of the newborn's capacity for contingency detection), wherein both partners maintain a patterned relationships throughout play, that could also serve as a predictor of developmental outcomes. In Fogel's approach an understanding of dialogical processes may help one to appreciate how the dialogical self develops. All dialogues, real or imagined, in infants and adults, form regularly recurring routines, or frames, for coordinated mutual action. Frames are stable patterns of mutually coordinated activity related to the topic, setting and scope of the dialogue (Fogel, 1993). Frames, thus, are interaction rituals such as greeting and leave-taking, plots or themes of narratives, social games and patterned conflicts. They can be verbal or non-verbal. They require maintenance by participants to remain alive and rejuvenation or letting go when they begin to fall apart (Fogel, 1993). Rigid frames limit the opportunities for growth. Creative (flow) frames enhance self development. During participation in creative frames, the self is not an experience of being but an experience of becoming, a process of improvisational co-activity with potentially infinite possibilities for self discovery (e.g., Csikszentmihalyi, 1990, 1993; Dewey, 1934; Lavelly \& Fogel, 2005). Creative frames, therefore, are the locus of self developmental change. Fogel (1993) sets that within individual experience; there are moments when being and becoming are present in a fruitful and self-sustaining balance. One remains open to change while at the same time has a sense of stability and uniqueness. In an open conversation, for example, the participants begin with a frame of mind, a loosely defined set of orientations that partake of their individuality. Via co-regulation, each person opens to change but that change is integrated into their prior orientations, thus preserving their individuality and at the same time changing it. In this case, there is an intimate and directly perceived connection between self and other that has the special quality of being co-creative. One is aware of the self, one is aware that the other is a self, and one is aware that the emergence of those selves (as events) depends upon the co-creative process (as mutual orientations) and the self-events are always "orientational”. Co-being arises from and flows into co-becoming.

Alternatively, in a developmental study of the microgenesis of form in scribbling (Stamatopoulou, 2011), "flow" has been revealed as an emergent "background" experience that gradually forms a motivational intermediate frame (fragile) that comes forward when motor-affective synchrony is reached in the activity (synchrony/interactive mirroring between action and production). Repeated instances of well coordinated drawn traces evolve in regulatory "flow experiences" that mark the organization of arousal and affects into positively flavored pattern durations that push the child's primary reactive space to be 
converted, through co-articulation, into the child's interactive space which has perspectival and expressive/communicative potential. Thus, the origin of positivity is inherently dyadic [(e.g., synchrony reached between the child and another human being, or between means-focused action/temporal regulation (I) and production/ends-focused action (Me)] and evolve in timethus, positivity is linked to background emotions and to temporal sequence that can be synchronized when fine motor tuning and gross motor intention overlap (see optimal performance) (Stamatopoulou, 2011). Reflecting on the impact of self-involvement in the production and recognition of drawings, recent findings suggest that visuo-motor coordination, indicating fluent mark-making, was the single most influential factor in the children's own drawing recognition (Ross, 2008). In scribbling then, motor-affective regulation originated an emerging relational organization in the experience that reciprocally grounded deeper engagement which generated an urge for formation/meaningfulness that resulted in the emergence of symbolic representations (Stamatopoulou, 2011). Optimal experience, thus, functions as a force for expansion when the child reaches an ordered state of consciousness, once becomes progressively absorbed (initially momentary) by the activity. Flow experience then, might provide an overall framework for the organization/schematization of the self, forming a (self)-regulatory background that fosters and sustains the child's coordinated attunement to the world/object (repetitive coordination of action and perception, or of the actor as subject (I) and as possible object $(\mathrm{Me})$, while initiating a differentiation between formative-action (means) and production (ends). That is, founding the emergence of self-recursive consciousness, selfreferential intentionality and reflection that results in the emergence of embodied experiential/perspectival self, originating symbolic expression/communication. Yet, this landscape is complex and dynamic assuming a transformational change and systematic novelty, not confined within some original base level (Stamatopoulou, 2011; Overton, 1999). Meanwhile, as far as further experimental evidence is rather lacking, we need further research to be undertaken to unravel many of these issues.

Besides that, some developmental researchers consider that the use of Csikzentmihalyi's concept of flow to refer to moments of the 1 year 7 month old's concentration and engagement is not a robust criterion. Their main objection derives from their credence that the imputation of adult states that are meant to characterize moments of extreme or out-of-the ordinary creative engagement, to the infant is not convincing, (and particularly when there is still considerable brain development that will occur). Still, the first arisen reservation towards the above objection concerns whether flow is strictly an adult state. Although it could be reasonable to consider that adults could experience a fully fledged flow experience, the conceptualization of flow as a situation where challenges are matched with the person's skills does not preclude flow instances for very young children, at the level they access some sort of coordination with significant others or music. At this point we possibly realize that our methodologies may need to become more sensitive to the child's live experience in means-ends activities.

A second question pertains to whether such an experience is an extreme one out of the realm of everyday life. If someone is familiar with the flow framework, he/she could probably easier tackle this. However there might be some points in the flow literature that have been misunderstood or need to be reconsidered, since when in flow we undergo an experience with multi- faceted qualities or complementary opposites. That is, the aspect of emergent control, or that of the full attunement of the subject to the world (a kind of coordinated motor-affective fusion with the activity and its attentional object) which also implies an experiential turn (immediate and embodied experience). At this point a paradox can be discerned, we speak about the phenomenology of a subjective experience while the experience is world/object focused having a turn-taking interacttive structure that allows coordination with the world/object. When approaching flow as a merging of the subject to the object resulting into an interactive coordinated embodied system, we possibly transcend the privacy of subjectivity and we probably face an experience that has the structure and the flavour of an intersubjective experience which is inherently a social communicative/expressive experience (see more about this later). If the above seems highly speculative, we may better think of music or dance (and infants do go with the music) and ask why? Of course music is a deeply socio-cultural resource, but still music is not a significant other. Possibly there are some ways to resolve such discrepancies, especially if we approach activities as dynamic, evolving in time and formative/constructive.

Infants' early movements often seem to lack meaning. Yet unlike covert mental events, motor behaviours are "out in the open” and also "become shaped” (Adolph \& Berger, 2006). The problem with approaches arguing that "from an action you will never get a symbol for it" is that they deny the possibility of transformational change and systemic novelty (Overton, 1999).

Perceiving, acting, and knowing approaches (e.g., Shaw \& Bransford, 1977) sometimes miss the essentially qualitative nature of movement, the fundamental nature of the "animate form”. They approach movement as a change of position or locomotion in the service of perception (Sheets-Johnstone, 1998). In contrast, experienced movement is folded into perception while co-regulated and modified by a wide array of coordinated emotional triggers ${ }^{1}$, such as our caregivers or music/dance. This point emphasizes the pervasive dynamics of movement and its cross-modal linkage to emotion, both of which are crucial for the developing infant, given that they establish a kind of primitive co-regulated space of intersubjective interaction among the infant, the caregiver, and the world (e.g., Haviland-Jones \& Kahlbaugh, 1993). Experienced/felt movement is the hallmark of animacy (Adolph \& Berger, 2006). These cross-modal patterns in which motor/affective expressions and regulation seem to be the first glue that holds the interaction together ${ }^{2}$, form embodied, embedded, practices of coordinated, co-regulated and co-articulated patterns of mutual immediacy and shared meaning (e.g., gestures) (Camaioni, Aureli, Bellagamba, \& Fogel, 2003; Fogel et al., 2002). Embodiment thus functions as a default social resonance mechanism that also sets the ground for the infant's expansion to interactive, coordinated and co-articulated abilities as found in any action-perception-production systems.

In any case, we call for more systematic empirical work to be undertaken to clarify instances of flow in children, bearing in

\footnotetext{
${ }^{1}$ See also terms such as intersubjective attunement (Stern, 1993); joint coordination with the other (Fogel \& Thelen, 1987).

${ }^{2}$ Haviland-Jones \& Kahlbaugh (1993) claim that emotion is the first-order "glue" of identity that creates chunks of experience through the process of emotional magnification (largely an intrapersonal process) and resonance (largely an interpersonal process).
} 
mind that, thought it is unlikely children at these ages to have access to the subjective phenomenology of their experience, we could investigate motor behaviors and attention modulation when children are engaged in "doing”, "playing”, "dancing”, "scribbling" ... Probably these activities wherein children can achieve some kind of "flow" are germinal to the differentiation of the self-world/other, forming another complementary field that some kind of co-regulation could arise.

Meanwhile, there might be some aspects in the framework of optimal experience approach that might be reconsidered, as I am going to suggest, which tackle on specific qualities of flow experience that possibly function in a double faced manner. First, I will roughly highlight some of these dimensions (e.g., regarding the interactive turn-taking structure of flow and the paradox of control), which might function counter intuitively when focusing on the developing person as especially related to the emergence of self-referential intentionality in means-ends activities that grounds symbolic functioning. In the last part of this article, attempting to offer another reading, I will set the frame wherein the first interpretative gap, in developmental literature, can be discerned disengaging flow from its potential contribution to the emergence of symbolic mind.

\section{The Puzzle of Flow Experience}

\section{Goals and Skills and the Paradox of Control and Absorption}

The ability to control the environment by limiting the stimulus field, finding clear goals and norms, and developing appropriate skills-is one side of the flow experience. The other side paradoxically, is a feeling which seems to make the sense of control irrelevant. Many people interviewed (Csikzentmihalyi \& Csikzentmihalyi, 1988), especially those who most enjoy whatever they are doing mentioned that at the height of their involvement with the activity they lose a sense of themselves as separate entities, and feel harmony and even a merging of identity with the environment. In such a state, thus, person and world form an embodied system. Although as the authors state, enjoyable activities that produce flow have a potential negative effect of becoming addictive at which point the self becomes captive of a certain kind of order and then unwilling to cope with the ambiguities of life (see flow as a mood regulatory mechanism; see also Delle Fave \& Massimini, 2003).

Accordingly, the flow experience is typically described as involving a sense of control—or, more precisely, as lacking the sense of worry about loosing control that is typical to instrumental functioning (or telic mode in Reversal theory; see Apter, 1984) of every day life. The important thing to realize, here, is that flow activities are so constructed as to allow the practitioner to develop sufficient skills to reduce the margin of error while at the same time what people enjoy is not the sense of being in control, but the sense of exercising control as perceived possibility of control (Csikzentmihalyi, 1993: p. 61). In flow, thus, control is emergent than set a-priori, while recentering self organization.

What should be emphasized here is that when children become gradually engaged in the action, they progressively concentrate in a narrowed attentional space. Apparently, this emergent flow dimension, qualifies a more stabilized expressive-communicative than reactive frame. That is, children manage to coordinate the means and the ends of the activity at a psychological level of functioning forming an inclusive embodied system - of which they became an integral part (Stamatopoulou, 2011). This action, by itself rewarding, sustains concentration, which leads to further involvement, which in turn is maintained by constant inputs of attention and implicit goal organization (see flow; Csikszentmihalyi, 1997). Thus, the ability to control the environment by limiting attentive stimulus while coordinating with the activity leads to the reduction of errors in performance (e.g., overshooting) and induces a sense of exercising control and the perceived possibility of prospective control. Engagement in action and attention modulation gradually signals the possibility of having access to experiential content (what it feels like from inside; Lambie \& Marcel, 2002; Csikszentmihalyi, 1997). Yet, the capacity for entering, experiential states is characterised by marked cognitive restructuring (Werner \& Kaplan, 1963).

\section{The Paradox of the Turn-Taking Structure of Flow that Transcends Subjectivity and Implies Meaningfulness}

When focusing on the autotelic quality of flow isolating it from its dynamic - temporal organization, we might end up underestimating implications that might be related to its deeply interactive turn-taking structure, wherein the experience is world-focused/other-focused-that is, an open experience of becoming rather than of being, constrained by its manifestation-an on-going co-articulation of action and production. As stated above, this schema, although pertains to the development of experiential subjectivity, holds a deeply relational structure. In fact, flow forms this kind of experience when the person is tuned to the word/object in its most open attitude to co-regulate with the object-this is in fact an expressive-communicative mode and not just a self-indulging mode characterized by its privacy (see Werner \& Kaplan, 1963).

At the same time, the aspect that is really not well highlighted is that the evolving in time, mirroring structure of flow activities (the dynamic co-ordination and co-regulation of the person and the world/object other wherein the demands of the structure are entities in themselves-co-articulation when temporal dynamics become schematized), initiate a reciprocal feedback between action and production/perception (meansends system where the means are the ends) that facilitates anticipatory control (proxy) and a proxy or background intentionality that imbues meaningfulness to the activity. Regulation seems to be the first glue holding the interaction together (fragile). Yet, this newly emergent mediated sense of agency (see proxy control) originates meaningfulness to the activity (Stamatopoulou, 2011). It is thus, germinal for the differentiation of means-ends, or contingencies from efficacies, or self from other/object dissociated from the direct sensorimotor action and from direct perception.

\section{The Experiential and the Embodied Qualities: Possible Implications for the Emergence of Embodied/Perpectival Self and Self-Referential Intentionality}

In a more theoretical manner, any rhythmic coordinated (flow) activity (even experienced in our immediate past) acts as a coordinator or unifier, constructing consciousness as integrated awareness (Churchland, 1986). Integrated awareness as 
proprioceptive feedback about what movement was actually made as "felt from inside" and anticipatory perceptual action (that maintains position in the external space) makes a dynamic match. It is suggested that this match ascribes to a "supramodal representational system" the ability to become co-articulated as a schematic form that is shared reciprocally by both sides of the embodied system (action as felt from inside and production as seen externally (Meltzoff \& Gallagher, 1996). This aspect highlights the "for-me-ness" quality of our actions by providing a "sense of ownership" for the body and its movements. Thus, it is germinal to a primitive first-person experience of embodiment, which is a basic part of the self/object distinction (Gallagher, 2003; Lambie \& Marcel, 2002; Overton, 1999; Rochat, 2003). That is, flow/optimal performance where fine motor tuning and gross motor intention overlap, intrinsically have some implicit underlying influence on the contents of conscious experience (Stamatopoulou, 2011). Consequently these relational structures, being still of a motor-affective deeply rooted origin, hold a generative representational status (visual and symbolic), upholding the emerging differentiation between the symbol and the object (see also Baldwin, 1894).This entails a shift from a relatively differentiated (implicit) sense of self (body) developing from birth to a progressive differentiation towards explicitness-between the self as an inner/experiencing subject and as an outer/object (the emerging embodied self and I-me relationships). This is the cornerstone for the reflective thought processes (Rochat \& Striano, 2002).

More, specifically, this process of "objectifying" the action outcomes in overlapping means-ends activities pushes the prereflective reference to the body as subject, or as existing within the act of perception (body schema), to be transformed into the reflectively aware body (body image). The actor, existing in the action of his own body, becomes the agentive self who controls his action by transforming the body-centered dynamic experience to an outlined, schematic unit/production. This objectified form, shaped interactively by the ongoing activity, is anchored both ways in the body while controlled deliberately. It will apparently therefore become self-referential by anchoring both poles of the "intentional arc" (self as subject and object; Gallagher, 2003; Tomasello, 1995; Zelazo, 2004). In this sense, an integrative differentiation occurs between means-focused (temporal regulation) and ends-focused action (e.g., fixing the circle) that allows an altering of both extremes-which also implies a sort of flexibility in accommodating both (Bandura, 1982). Thus, materials or configural forms are transformed into potential communicative tools through dynamic schematization processes (see de-differentiation and differentiation in Werner \& Kaplan, 1963).

\section{Optimal Performance Calls for Variation}

Optimal performance, standing as a "core" value (attractor) for the dynamic system of means-ands activities, indicates coordination of component processes and subsystems, so as to form an integrated whole that goes beyond the component parts by themselves (Fischer \& Bidell, 1998). This suggests that the "core" calls for differentiation, and gears children into the experiential (expressive/communicative) flow mode that redirects or sustains attention to the world. This is vital to any developmental trajectory in which more complex values develop in relation to core values (Thelen \& Smith, 1998; Csikszentmihalyi, 1998; see also de-differentiation and hierarchical integra- tion).

\section{An Interpretative Gap in Developmental Literature}

\section{Two Motivational Mechanisms: Circular Reactions and Positive Self-Attribution Bias}

It is quite unclear from the recent developmental literature how trivial-seeming activities, forming circular reactions, or response-contingent activities, can contribute to the understanding of means-end and causal relations with respect to symbolic functioning and communication (Stamatopoulou, 2011). Although we may be inclined to analyze response-contingent reactions that gradually form means-ends activities (e.g., scribbling) solely in terms of the infants' responsiveness to "behaviour", the extreme alternative is to suppose that such young infants already have a sophisticated concept of selfreferential behaviour, or it could be that through such behaviour infants come to understand self-referential intentional communication/expression (Tomasello, 1995).

Fischer and Connell (2003) argue that two kinds of motivation are key mechanisms that together drive and shape emotional and cognitive development: "circular reactions" that promote the development of skills and knowledge of the world (epistemic motivation); and "positive self-attribution bias" (self-organizing motivation), which promotes immediate constant appraisals for detecting what is good/bad for self, creating positive self-bias and leading to the construction of stable patterns of activities based on long-term goals involving self and others (representation of mental states). Response-contingent activity (circular reactions) promotes positive emotions and leads directly to growth of knowledge and skills (Csikszentmihalyi, 1997, 1998; Fischer \& Connell, 2003; Schmuckler \& Jewell, 2006). Both forces operate through an underlying affectively organized mechanism which detects interesting response-contingent configurations or change/error that is immediately appraised. Both organize a feedback process that controls immediate behavior, since as infants grow they develop through these activities the capacity to monitor their action tendencies and often adjust them before carrying out an overt act (co-articulation). This is basic for an implicit self-knowledge (body sense) in very young infants and grows in parallel to developing action systems that entail intermodal co-engagement of proprioception plus other modalities, underpinning the latterly developed conceptual self-awareness (Rochat \& Striano, 2000; Watson, 1984). This ability to transform reactive or contingent behavior into positive, coordinated, interactive, expressive scripts is also fundamental to the development of social and emotional communication (Feldman, 2007; Csikszentmihalyi, 1997, as cited in Fischer \& Connell, 2003; Fogel, Koeyer, Ballagamba, \& Bell, 2002).

There is speculative evidence of how these two motivational forces could be functionally linked to shape experience, intentional action, selfhood, and symbolic function. Fischer's proposal, whereas brings them to the fore, implicitly entails a folded dichotomy between "circular reactions" that lead to cognitive development and the self-organizing motivation ("how I or others act/should act”) that lead to socio-emotional communication. It appears that the option of circular reactions tied to behavioral control, loses its ties with the affective background that drives it. Thus, it loses its evaluative, regulatory/motivating 
significance for oneself, and thus its potential contribution to self-organizing biases toward the self/other and to symbolic function (i.e., the consequences of self-control for the representation of mental states in later development). Yet the relation between "self-imitative repetition" of a pleasurable response and the emergence of a generative imitation that holds representational potential is a key to circular reactions (cf. Baldwin, 1894).

Although the exact mechanism by which behavioral states (i.e., scribbling) associated with positive affect produce goaldirected motivational behavior is only partly understood, the bottom line could be that positive shaping of these behavioral states depends on those particular forms of caregiver interaction during infancy that are required for the development of emotion/behaviour regulation (Feldman, 2007). A residual issue could be why children or adults are captured by captivating contingencies (Watson, 1984). This option can either be seen as an motivational force that sustains the mastering of skills (Fischer \& Connell, 2003), or as a background affective regulatory underlying mechanism that promotes positive affectivity-seen as an emerging mediating motivational frame, which consequently generates attunement to the world (redirecting attention in the world) and openness to becoming interactively involved in world/other-centered experiences that do not exclude objects or actions/events of interest (Csikszentmihalyi, 1998). This alternative, that allows new forms of selfregulation to emerge, stresses the role of experience in the development of selfhood while suggesting a bi-directional relation between self control and the emergence of representational insights. Thus, instead of behavior regulation, it stresses the dynamic self-other/object relationship that creates chances for positive self-regulation and emerging complexity as the child's index of taking on integrating and differentiating complex relationships, including (but not exclusively) relationships with other people (Stamatopoulou, 2011). Counter intuitively, there might be an underappreciated relation between circular reactions and means-end behavior that promotes goal-directed intentional action through self-monitoring, and self-other differentiation which is germinal to symbolic communication (Schmuckler \& Jewell, 2006). By incorporating the impact of the affective/motivational organization of “doing/making” (i.e., scribbling) on means-end understanding and on the representation of goals, we may reveal that the emergence of the flow dimension in experience contributes to increasing insights into the intentional nature of action, production and self, which all support differentiation, self-referential intentionality, along with the emergence of the embodied, and latterly, self-reflective agentive self. The underlying key is the relation between action, event, and production to temporal regulation that marks the emergence of co-articulation/flow which in line stabilizes background emotion (positivity) motivational frame. In this case, flow can be seen both as an antecedent and an outcomea reciprocally differentiating and integrating mechanism to means-ends, to selfhood. Yet, these upcoming relationships are not direct but mediated by the emergence of the flow modethis is the difficulty to be realized in development (Stamatopoulou, 2011).

Specifically, it is the interactive, "turn-taking" organization of the system (i.e., scribbling as an interactive action-production system), initially developed from birth in coordination with a primary caregiver (Rochat \& Striano, 2002), that creates a shift from things-of-action (instrumental) to things-of-wonder (contemplative stance), thus justifying active explorative behavior that has expressive/communicative potential, where (gradual) engagement in action (amusement is of a medium degree) functions as a self-regulatory experience (Stamatopoulou, 2011). Similarly, the pleasure initially experienced in the process of experiencing contingencies by producing coordinated undifferentiated means-end events functions as an affective force that sustains repetition, fostering re-engagement (active/creative exploration) into the dynamic person-other/object relationship, so as to form an integrated embodied system (Csikszentmihalyi, 1997, 1998; for a discussion about imperfect contingencies see Watson, 1984; Rochat \& Striano, 2002; Schmuckler \& Jewell, 2006). Degrees of coordination with the system constitute degrees of engagement into a "humanlike" interactive dynamic system which, for this particular reason, undergoes qualitative gradual changes in relation to selfhood. This possibility, drawn from Csikszentmihalyi's work on optimal experience, complexity, and development and in some conjunction with Rochat's work on the development of self-awareness, promotes anticipatory action and corrective perceptual monitoring (flow, co-articulation and prospective anticipatory control) by fostering attentional and intentional focus. Thus, it facilitates the system's adaptability, initiating differentiation, so that a shift (decoupling) in a loop fashion between the external and internal sides of the embodied system is enabled, progressively permitting experiential-phenomenological reflection and reflective awareness of "what it feels like" from inside. This in turn allows the reflective valuation of outcomes within the wider social context, while maintaining the coherent organization and functional unity of the child and its world (Csikszentmihalyi, 1998; Gallagher, 2003; Lambie \& Marcel, 2002; Rochat, 2003).

This residual option could be enhanced by arguing for the inherently value-laden affective character of perceptual experience in infancy which, attuned to the world or others, transforms reactive actions to interactive patterns that become contemplative/realized events, structuring self-referential intentionality that carries perspectival and thus expressive/communicative potential (Hobson, 1993; Werner, 1957). This implied partial shift of function is enabled through means-ends imitative acts that stabilize the differentiation between behavioral-instrumental and experiential functioning and foster experiential learning - novel category formation, and the development of protosymbolic abilities (Hobson, 1993). Thus, at least partly, an individual's potential for more detached forms of cognitive appraisal, evaluation, and elaboration develops out of such primary models of "cognitive-cum-affective" relatedness, not inclusively restricted to persons (cf., Werner's [1954] view on physiognomic perception ${ }^{3}$ ). This ultimately implies an intersubjective dimension in any "flowing", ongoing learning/doing process. This stance neither denies the social origins of the mind nor the child's ability to have lived experiences; on the contrary, it stresses the "affective attitude" of the child's perceptual experience in infancy (Werner, 1957). Accordingly, self-imitative movement repetitions perceivable in means-ends

\footnotetext{
${ }^{3}$ Werner (1954), dealing with expressive symbolism, argued of two deferent modes of perception: the physiognomic and the geometric/technical. The physiognomic mode, implicit in our everyday life (although quite explicit in infancy) becomes strikingly explicit in the phenomena of empathic responses, and comes to the forefront in the spheres of myth, art, and religion. It is characterized by its pervasive dynamics, the relative lack of differentiation of self/world, the total organismic involvement, and the embeddedness of the perceived object in an atmospheric context of feeling and action.
} 


\section{STAMATOPOULOU}

activities could/should carry perspectival and symbolic potential.

\section{Conclusion}

It is still hard to reconcile cognitive, socio-emotional, visual, and behavioral approaches to set a frame, but instead of assuming that undifferentiated means-ends actions are just repeated behavioral patterns seeking regulation, or at best "circular behaviors" for the child's amusement, we could rather better look at those "intermediate" activities that by experience unfolding in time set a background (emerging flow mode) that contributes to the emergence of intentionality in means-end activities. As such, they facilitate the gradual emergence of the "becoming fully embodied", perspectival self, which is germinal to symbolic/representational development (Hobson, 1993).

That is, mean-ends activities when reach optimal states (see flow) function as a "morphosyntactic" field that provides children with self-coherence and the experience of the body as a possible multimodal object-a coordinated but also gradually differentiated outside and inside in a psychological sense (Stamatopoulou, 2011). It is this embodied/experiential quality of the schematizing processes (form-building or schematized embodiment) of flow that operate in a regulatory, directive manner on both sides, which ultimately binds together the vehicular form (production/symbol) to its embodied matrix (formative action) and gives self-referential meaning to it (Werner \& Kaplan, 1963). This also means an advanced abstraction of the body schema signified by his intentional control of the interplay between these two tightly coupled facets (formative action-means and production-ends), which initiates a distancing-a decoupling between them. This act might model agentivity at a sufficient and necessary level for initiating symbol formation, that grounds the action's significance and give rise to the "signification" of the production/form.

Thus, background positive affectivity that steams from flow dynamic experiences could provide the backdrop against which actions, perceptions, (inter)personal expressive/communicative acts, and symbols/mental products are formulated. Prospective developmental research is required to understand the nature of the background positive affectivity of flow experiences and its transformation to this intermediate motivational mode that accommodates temporal dynamics of ongoing activities. Yet, this is the bottom line that sets the base for the emergence of this motivational frame that allows playfulness through the flow mode which is also linked to the emergence of consciousness in infancy (Fogel et al., 2002, call this "creative frame" and refer to Csiksentmihalyi, 1990; Fischer \& Connel, 2003, adopt the same approach). In fact, we are in need of further developmental research on the reciprocal relationships of the motivational, emotional and cognitive components of flow experience, since we know little about its role regarding symbolic functioning and its contribution to the consolidation of the self as agent.

\section{REFERENCES}

Adolph, K. E., \& Berger, S. E. (2006). Motor development. In D. Kuhn \& R. S. Siegel (Eds.), Handbook of child psychology: Vol. 2: Cognition, perception and language (6th ed., pp. 161-213). New York: Wiley.

Apter, M. (1984). Reversal theory, cognitive synergy and the arts. In W. R. Crozier, \& A. J. Chapman (Eds.), Cognitive processes in the per- ception of art (pp. 411-426). Amsterdam: North Holland. doi:10.1016/S0166-4115(08)62361-4

Baldwin, J. M. (1894). Imitation: A chapter in the natural history of consciousness. Mind, 3, 26-55. doi:10.1093/mind/III.9.26

Bandura, A. (1982). Self-efficacy mechanisms in human agency. American Psychologist, 37, 122-147. doi:10.1037/0003-066X.37.2.122

Bard, K. (2008). Understanding reflections of self and other objects. In C. Lange-Kuttner, \& A. Vinter (Eds.), Drawing and the non-verbal mind (pp.23-41). Cambridge: Cambridge University Press. doi:10.1017/CBO9780511489730.002

Brandstadter, J. (1998). Action perspectives on human development. In W. Damon, \& R. M. Lerner (Eds.), Handbook of Child Psychology (Vol. 1, pp. 807-863). New York: Wiley.

Camaioni, L., Aureli, T., Bellagamba, F., \& Fogel, A. (2003). A longitudinal examination of the transition to symbolic communication in the second year of life. Infant and Child Development, 12, 1-26. doi:10.1002/icd.333

Churchland, P. S. (1986). Neurophilosophy: Toward a unified science of the mind-brain. Cambridge, MA: MIT Press.

Csikszentmihalyi, M. (1975). Beyond boredom and anxiety. San Francisco, CA: Jossey Bass.

Csikszentmihalyi M., \& Csikszentmihalyi, I., (1988). Optimal experience. Psychological studies of flow in consciousness. New York: Cambridge University Press. doi:10.1017/CBO9780511621956

Csikszentmihalyi, M. (1993). The evolving self. New York: Harper \& Row.

Csikszentmihalyi, M. (1997). Finding flow: The psychology of engagement with everyday life. New York: Basic Books.

Csikszentmihalyi, M. (1998). The development of the person: An experiential perspective on the ontogenesis of psychological complexity. In W. Damon, \& R. M. Lerner (Eds.), Handbook of Child Psychology (Vol. 2, pp. 635-684). New York: Wiley.

Csikszentmihalyi, M., \& Massimini, F. (1985). On the psychological selection of bio-cultural information. New Ideas in Psychology, 3, 115-138. doi:10.1016/0732-118X(85)90002-9

Csikszentmihalyi, M., \& Robinson, R. E. (1990). The art of seeing. Malibu, CA: The Paul Getty Trust Office of Publications.

Delle Fave, A., \& Massimini, F. (2003). Drug addiction: The paradox of mimetic optimal experience. In J. Henry (Ed.), European positive psychology proceedings (pp. 31-38). Leicester: British Psychological Society.

Delle Fave, A. (2007). Individual development and community empowerment: Suggestions from studies on optimal experience. In J. Haworth, \& G. Hart (Eds.), Well-being: Individual, community, and societal perspectives (pp. 41-56). London: Palgrave McMillan.

Delle Fave, A., Bassi, M., \& Massimini, F. (2008). Optimal experience and psychological selection. In C. Vasquez, \& G. Hervas (Eds.), Positive psychology: Scientific bases of well-being and resilience (pp. 209-230). Madrid: Alianza Editorial.

Dewey, J. (1934). Art as experience. New York: Perigee.

Feldman, R. (2007). On the origins of background emotions: From affect synchrony to symbolic expression. Emotion, 7, 601-611. doi:10.1037/1528-3542.7.3.601

Fischer, K. W., \& Bidell, T. R. (1998). Dynamic development of psychological structures and thought. In W. Damon, \& R. M. Lerner (Eds.), Handbook of Child Psychology (Vol. 1, pp. 467-561). New York: Wiley.

Fischer, K. W., \& Connell, M. W. (2003). The two motivational systems that shape development: Epistemic and self-organizing. British Journal of Educational Psychology, Monograph Series II, 2, 102 123.

Fogel, A. (1993). Developing through relationships: Origins of communication, self, and culture. London: Harvester-Wheatsheaf, Chicago, IL: University of Chicago Press.

Fogel, A., de Koeyer, I., Ballagamba, F., \& Bell, H. (2002). The dialogical self in the two years of life. Theory \& Psychology, 12, 191205. doi:10.1177/0959354302012002629

Fogel, A., \& Thelen, E. (1987). Development of early expressive and communicative action: Reinterpreting the evidence from a dynamic systems perspective. Developmental Psychology, 23, 747-761. 


\section{STAMATOPOULOU}

doi:10.1037/0012-1649.23.6.747

Gallagher, S. (2003). Bodily self-awareness and object-perception. Theoria et Historia Scientiarum: International Journal for Interdisciplinary Studies, 7, 53-68.

Gallese, V. (2005). Embodied simulation: From neurons to phenomenal experience. Phenomenology and the Cognitive Sciences, 4, 23-48. doi:10.1007/s11097-005-4737-z

Haviland-Jones, J. M., \& Kahlbaugh, P. (1993). Emotion and identity. In M. Lewis, \& J. M. Haviland-Jones (Eds.), The handbook of emotions (pp. 327-339). New York: Guilford.

Hobson, R. P. (1993). The emotional origins of social understanding. Philosophical Psychology, 6, 227-249. doi:10.1080/09515089308573090

Jackson, S. A. (1992). Athletes in flow: A qualitative investigation of flow states in elite figure skaters. Journal of Applied Sport Psychology, 4, 161-180. doi:10.1080/10413209208406459

Kerr, J. H. (1997). Motivation and emotion in sport. Hove: Psychology Press.

Lambie, J. A., \& Marcel, A. J. (2002). Consciousness and the varieties of emotion experience: A theoretical framework. Psychological Review, 109, 219-259. doi:10.1037/0033-295X.109.2.219

Lavelli, M., Pantoja, A. P. F., Hsu, H., Messinger, D., \& Fogel, A. (2005). Using microgenetic designs to study change processes. In D. M. Teti (Ed.), Handbook of research methods in developmental science (pp. 40-65). Malden, MA: Blackwell. doi:10.1002/9780470756676.ch3

Meltzoff, A. N., \& Gallagher, S. (1996). The earliest sense of self and others: Merleau-ponty and recent developmental studies. Philosophical Psychology, 9, 211-233. doi:10.1080/09515089608573181

Mounoud, P. (1999). What is homeopathic when you overdose? In Peer commentaries on James Russell's "Cognitive development as an executive process-In part: A homeopathic dose of Piaget”. Developmental Science, 2, 271-288. doi:10.1111/1467-7687.00073

Niedenthal, P. M., Barsalou, L. W., Winkielman, P., Krauth-Gruber, S., \& Ric, F. (2005). Embodiment in attitudes, social perception, and emotion. Personality and Social Psychology Review, 9, 184-211. doi:10.1207/s15327957pspr0903_1

Overton, W. F. (1999). Nativism, empiricism and developmental dynamic action systems. In Peer commentaries on James Russell's "Cognitive development as an executive process-In part: A homeopathic dose of Piaget”. Developmental Science, 2, 271-288.

Rochat, P., \& Striano, T. (2000). Perceived self in infancy. Infant Behavior and Development, 23, 513-530. doi:10.1016/S0163-6383(01)00055-8

Rochat, P., \& Striano, T. (2002). Who's in the mirror? Self-other discrimination by four- and nine-month-old infants. Child Development, 73, 35-46. doi:10.1111/1467-8624.00390

Rochat, P. (2003). Five levels of self-awareness as they unfold early in life. Consciousness and Cognition, 12, 717-731. doi:10.1016/S1053-8100(03)00081-3
Ross, J. (2008). Drawing production, drawing re-experience and drawing re-cognition. In C. Lange-Kuttner, \& A. Vinter (Eds.), Drawing and the non-verbal mind (pp.42-62). Cambridge: Cambridge University Press. doi:10.1017/CBO9780511489730.003

Schmuckler, M. A., \& Jewell, D. T. (2006). Infants' visual-proprioceptive intermodal perception with imperfect contingency information. Developmental Psychobiology, 49, 387-398. doi:10.1002/dev.20214

Shaw, R., \& Bransford, J. (1977). Perceiving, acting, and knowing. Hillsdale, NJ: Erlbaum.

Sheets-Johnstone, M. (1998). The primacy of movement. Amsterdam: Benjamins P.C.

Stamatopoulou, D. (2004). Integrating the philosophy and psychology of aesthetic experience: Development of aesthetic experience scale. Psychological Reports, 95, 673-695.

Stamatopoulou, D. (2011). Symbol formation and the embodied self: A microgenetic case-Study examination of the transition to stmbolic commumication in scribbling activities from the 14 to 31 months of age. New Ideas in Psychology, 29, 162-188. doi:10.1016/j.newideapsych.2010.09.001

Stein, B. E., \& Meredith, M. A. (1993). The merging of the senses. Cambridge, MA: MIT Press.

Stern, D. N. (1993). The role of feelings for an interpersonal self. In U. Neisser (Ed.), The perceived self: Ecological and interpersonal sources of self-knowledge (pp. 205-215). Cambridge: Cambridge University Press.

Thelen, E., \& Smith, L. B. (1998). Dynamic systems theories. In W. Damon, \& R. M. Lerner (Eds.), Handbook of child psychology (Vol 1, pp. 563-634). New York: Wiley.

Tomasello, M. (1995). Understanding the self as social agent. In P. Rochat (Ed.), The self in early infancy: Theory and research (pp. 449-460). Amsterdam: North-Holland. doi:10.1016/S0166-4115(05)80024-X

Watson, J. S. (1984). Bases of causal inference in infancy: Time, space, and sensory relations. In R. Collier, \& L. Lipsitt (Eds.), Advances in infancy research (pp. 152-165). Norwood, NJ: Albex.

Werner, H. (1954). Studies in physiognomic perception: Effects of configurational dynamics and meaning-induced sets on the position of the apparent median plane. Journal of Psychology, 38, 51-65. doi:10.1080/00223980.1954.9712914

Werner, H. (1957). Comparative psychology of mental development. New York: International University Press.

Werner, H., \& Kaplan, B. (1963). Symbol formation: An organismicdevelopmental approach to language and the expression of thought. New York: Wiley.

Zelazo, P. D. (2004). The development of conscious control in childhood. Trends in Cognitive Sciences, 8, 12-17. doi:10.1016/j.tics.2003.11.001 